\title{
TOPENG KLASIK GAYA YOGYAKARTA DAN KREATIF MODERN KARYA SUPANA PONOWIGUNA KAJIAN FUNGSI, GAYA, DAN STRUKTUR
}

Arif Suharson¹ (arifkeramos@yahoo.com, Jurusan Kriya Fakultas Seni Rupa Institut Seni Indonesia Yogyakarta)

\begin{abstract}
The culture of mask has been in existence for a very long time ago. A number of archeological studies have found various types of mask since the prehistoric era thousand years ago. The historical data have revealed some important information on the usage of masks in human life in their interaction with the nature. These findings will be beneficial for the improvement of contemporary moment. They will also serve as the scientific reference to identify the materials, process, and development. When we observe carefully, Indonesia is rich of various kinds of traditional culture such as the mask art. Masks have unique characteristics depending on their origin. Masks are created intentionally to represent magical or ritual purposes. They also serve as the decorative or social symbols in the societies. Therefore, the existence of mask art has become a part of social culture. The creative creation of masks has represented the intellectual establishment of the artisans to comply with the ongoing social development. Therefore, we have classic, modern, and contemporary masks as the manifestation of the developing era and the satisfaction of transformative artistic artisans in visual arts.
\end{abstract}

Keywords: mask, culture, creative, creation

\begin{abstract}
ABSTRAK
Budaya topeng telah ada sejak dahulu kala. Sejumlah penelitian arkeologi telah menemukan berbagai jenis topeng sejak zaman prasejarah seribu tahun yang lalu. Data historis telah mengungkapkan beberapa informasi penting tentang penggunaan topeng dalam kehidupan manusia dalam interaksinya dengan alam. Temuan ini akan bermanfaat untuk peningkatan momen kontemporer. Mereka juga akan berfungsi sebagai referensi ilmiah untuk mengidentifikasi bahan, proses, dan pengembangan. Ketika kita amati dengan cermat, Indonesia kaya akan berbagai jenis budaya tradisional seperti seni topeng. Masker memiliki karakteristik unik tergantung pada asalnya. Topeng diciptakan dengan sengaja untuk mewakili tujuan magis atau ritual. Mereka juga berfungsi sebagai simbol dekoratif atau sosial dalam masyarakat. Karena itu, keberadaan seni topeng telah menjadi bagian dari budaya sosial. Pembuatan topeng yang kreatif telah merepresentasikan pembentukan intelektual para pengrajin untuk mematuhi perkembangan sosial yang sedang berlangsung. Oleh karena itu, kami memiliki topeng klasik, modern, dan kontemporer sebagai perwujudan dari era yang sedang berkembang dan kepuasan para pengrajin artistik transformatif dalam seni visual.
\end{abstract}

Kata kunci : topeng, budaya, kreatif, kreasi 


\section{PENDAHULUAN}

Kajian ini menekankan pada hasil kreasi seniman topeng klasik gaya Yogyakarta sampai pada karya topeng kreatif modern yang bernama Supana Ponowiguna yang ada di wilayah Yogyakarta tepatnya di Dusun Diro, Pendowoharjo, Sewon, Bantul. Seniman ini merupakan seniman kriya tradisional yang masih eksis memproduksi topeng berbahan kayu dan memiliki keunggulan dalam menciptakan kreasi topengnya. Topeng klasik gaya Yogyakarta yang dibuat mengambil cerita dari Panji (babad Gedhog). Prinsip pembuatan topeng klasik ini ikut berupaya melestarikan seni tradisi topeng klasik gaya Yogyakarta yang dikreasikan berdasarkan dari proses pembelajaran tiga sumber penting, yaitu: 1) Empu topeng gaya Yogyakarta, Empu Warno Waskito; 2) Ontleer Tiwi Kromo/Kyai Cakra yang merupakan pembuat topeng zaman kolonial Belanda; dan 3) Pedalangan/Topeng dalang/Topeng Arangan. Dari sumber-sumber tersebut kemudian dimunculkan gaya, bentuk, kreasi, dan inovasi seni topeng ala Supana Ponowiguna yang memiliki ciri khas tersendiri.

Kehidupan seorang seniman juga tidak bisa dilepaskan dari kehidupan lingkungan alam dan masyarakat sekelilingnya yang dapat memengaruhi proses berkarya. Kehidupan ini akan membentuk karakter seorang seniman. Hasil karyanya tidak akan bisa total lepas dari kebudayaan sebelumnya. Terlebih dalam menghasilkan karya seni yang bersifat seni tradisional keberadaan kebudayaan yang mengakar kuat seperti budaya keraton Yogyakarta Hadiningrat dijadikan sebagai patokan atau aturan yang tidak tertulis tapi melekat kuat menempel dalam hasil karya seniman tersebut. Seperti seni topeng yang merupakan hasil kebudayaan masyarakat yang dipercaya mengandung ajaran luhur dalam kehidupan masyarakat. Seni topeng karya Supana Ponowiguno juga berpedoman pada ajaran dari keraton yang memberikan ciri khas topeng Yogyakarta.

Melihat visualisasi bentuk-bentuk topeng karya Supana Ponowiguna yang memiliki karakter dan cirri khas tersebut, perlu adanya kajian ilmiah dengan melakukan penelitian untuk mengetahui aspek fungsi, gaya, dan struktur serta kajian ilmiah yang mendukung agar proses kreatif penciptaan karya topeng menjadi sumber ilmu yang dapat menjadi bahan kajian ilmiah tentang seni topeng. Hal ini penting untuk dilakukan agar keahlian membuat seni topeng tidak menjadi mati dan keilmuan membuat seni topeng dapat ditularkan kepada generai penerus bangsa. Bahkan kreativitas dalam menciptakan karya seni topeng seperti yang telah dilakukan Supana Ponowiguna telah mampu mengembangkan bentuk-bentuk topeng yang lebih inovatif tetapi tetap berkarakter Jawa khususnya gaya Yogyakarta yang merupakan aset penting bagi kebudayaan bangsa Indonesia.

Pemaparan mengenai bagaimana fungsi, gaya, dan struktur bentuk topeng dalam kreasi serta ekspresi seni topeng karya Supana Ponowiguna, juga perkembangan seni topeng klasik gaya Yogyakarta sampai pada karya kreatif modern karya Supana Ponowiguna dalam kancah seni rupa di Yogyakarta akan dijelaskan lebih lanjut di bagian pembahasan.

\section{PEMBAHASAN}

Topeng pedalangan gaya Yogykarta dalam sejarahnya baru muncul kira-kira tahun 1850, Sal Murgiyanto (1993: 110) yang juga dipelopori oleh para keluarga dalang. Mengingat di keraton Yogyakarta tidak memiliki tradisi pertunjukan topeng, bisa diduga bahwa kelahiran topeng pedalangan Yogyakarta diilhami oleh perkembangan wayang topeng di daerah Klaten yang juga didukung oleh para keluarga dalang. Namun karena para dalang di Yogyakarta terlebih yang menjadi abdi dalem keraton Yogyakarta merujuk pada pakeliran gaya Yogyakarta, kesenian topeng pedalangan pada dasarnya juga merujuk pada gaya Yogyakarta. Dalam arti gaya Yogyakarta yang telah diinterpretasi, dipersepsi oleh para dalang sesuai dengan nafas gaya pedalangan.

Perkembangan baru seni pertunjukan topeng Gaya Yogyakarta terjadi kira-kira tahun 1936 (Soedarsono, 1984:300). Dua bangsawan keraton Yogyakarta yaitu 
Pangeran Suryadiningrat dan Pangeran Tejakusuma melalui sekolah tari Krida Beksa Wirama mengembangkan tari topeng gaya Yogyakarta. Pertama tari topeng gaya Klasik sebagaimana dirintis oleh Krida Beksa Wirama, dan kedua ialah gaya pedalangan. Yang menarik peristiwa ini adalah bahwa tari topeng gaya pedalangan mulai diapresiasi oleh kalangan priyayi, lebih lanjut juga dimulai, dipelajari, dan ditarikan oleh para penari yang terbiasa membawakan tari-tarian klasik.

Studio topeng Supana Ponowiguna berada di wilayah Kabupaten Bantul tepatnya di Dusun Diro, Pendowoharjo, Sewon, Bantul. Seniman ini merupakan seniman kriya tradisional yang masih eksis memproduksi topeng berbahan kayu dan memiliki keunggulan dalam menciptakan kreasi topengnya. Topeng klasik gaya Yogyakarta yang dibuat mengambil cerita dari Panji (babad Gedhog). Prinsip pembuatan topeng klasik ini ikut berupaya melestarikan seni tradisi topeng klasik gaya Yogyakarta yang dikreasikan berdasarkan dari proses pembelajaran tiga sumber penting, yaitu: 1 ) Empu topeng gaya Yogyakarta, Empu Warno Waskito; 2) Ontleer Tiwi Kromo/Kyai Cakra yang merupakan pembuat topeng zaman kolonial Belanda; dan 3) Pedalangan/Topeng dalang/Topeng Arangan. Dari sumber-sumber tersebut kemudian dimunculkan gaya, bentuk, kreasi, dan inovasi seni topeng ala Supana Ponowiguna yang memiliki ciri khas tersendiri.

Penciptaan seni topengnya selalu dapat membuat karakter topeng sesuai dengan keinginan para penari dan para kolektor seni topeng yang menginginkan karya-karya seni topeng bergaya klasik, modern, dan kontemporer. Bahkan Supono juga sering membuat karya-karya topeng dalam bentuk boneka yang dapat dimainkan layaknya boneka dalam wayang golek maupun wayang Cina yang dalam menggerakkan tokohnya menggunakan tali. Keahlian membuat topeng ini beliau dapatkan dari ayahnya yang merupakan Empu pembuat seni topeng di keraton Yogyakarta, yakni Empu Warno Waskito yang sangat piawai dalam membuat topeng-topeng klasik untuk pertunjukan seni tari topeng pedalangan gaya Yogykarta. Supana Ponowiguno juga pernah mengenyam pendidikan di Jurusan Kriya ISI Yogyakarta yang secara tidak langsung akan memberikan dampak pada karya-karya topeng kreatifnya.

Karya-karya Empu Pono Wiguno yang kelahiran 1958 ini telah membuat topeng sejak tahun 1970. Dalam membuat topeng, Pono selalu mendalami karakter tokoh topeng dengan baik. Topeng-topeng karyanya telah melanglang buana ke seluruh dunia. Karyakarya topengnya juga telah dipakai oleh seniman dan panggung-panggung tari diberbagai bangsa. Satu benang merah yang menghubungkan semua topeng karyakaryanya ialah karakter. Semua topeng sangat jelas menggambarkan karakter yang kuat yang akan terlihat.Karya-karya yang dibuat berdasarkan pesanan khusus dari penaripenari kenamaan Indonesia sebut saja Didik Nini Thowok, Miroto, dan seniman tari ternama di Yogyakarta. Para seniman tersebut khusunya dalam seni pertunjukan tari sangat membutuhkan sentuhan kreatif Ponowiguna dalam menerjemhkan karakter yang diinginkan dalam tampilan seni pertunjukannya. Selain membuat topeng Ponowiguna juga sering membuat boneka yang digunakan dalam adegan wayang yaitu Wayang Golekan yang mirip dengan wayang golek dari daerah Sunda. Berikut beberapa contoh karya-karya topeng Supana Ponowiguna:

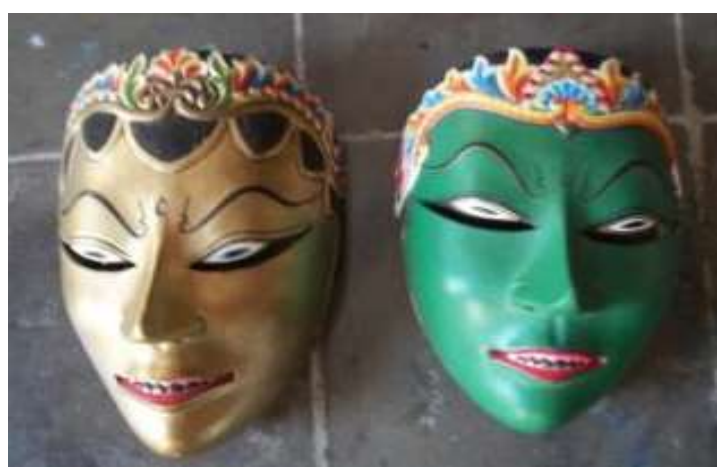



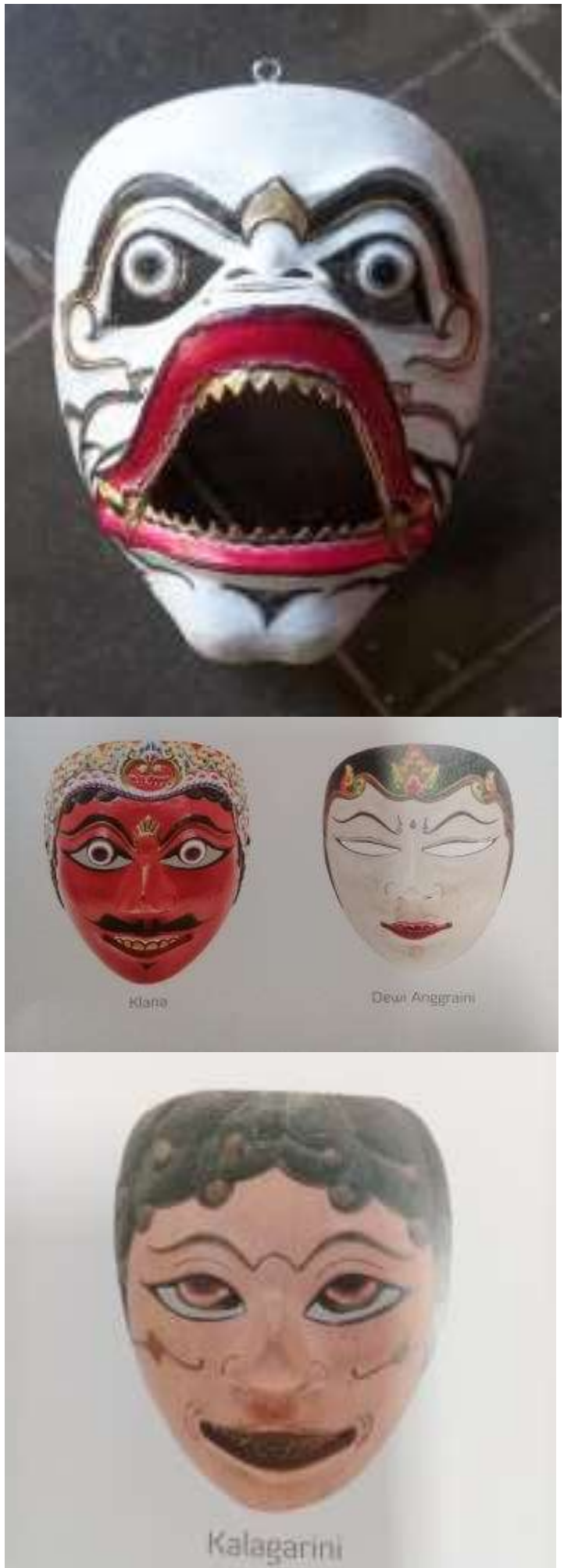

Gambar 1. Topeng Klasik Karya Supana Ponowiguno (Sumber: Katalog Pameran The Power of Topeng, 2015)

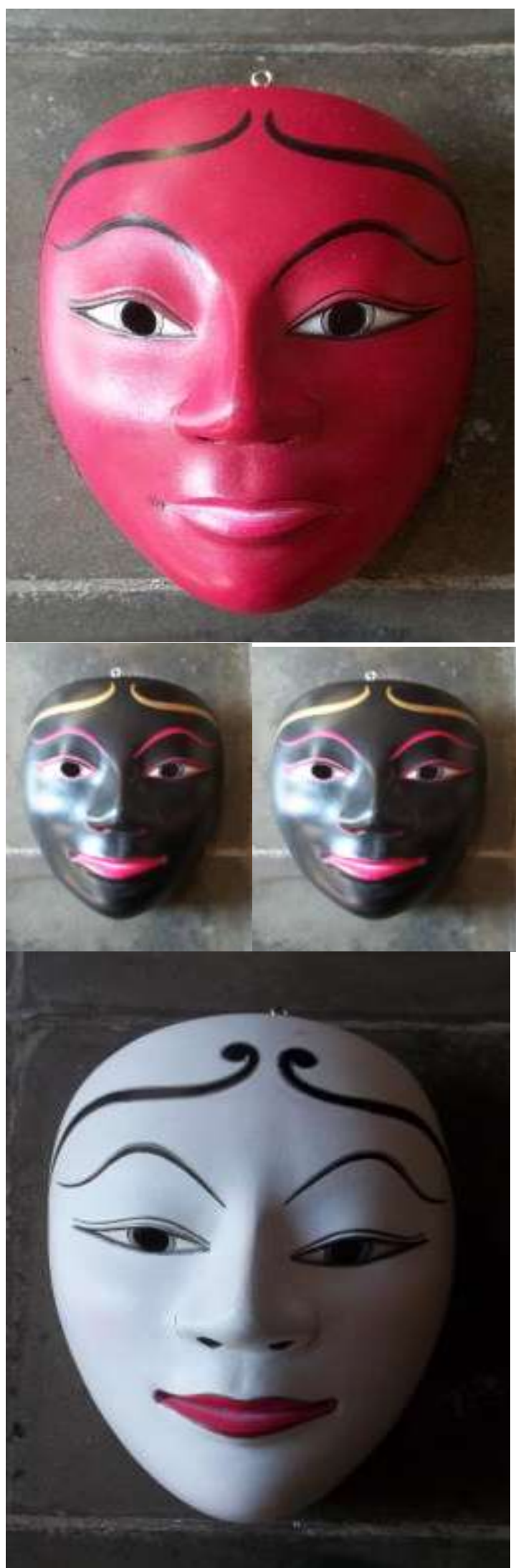



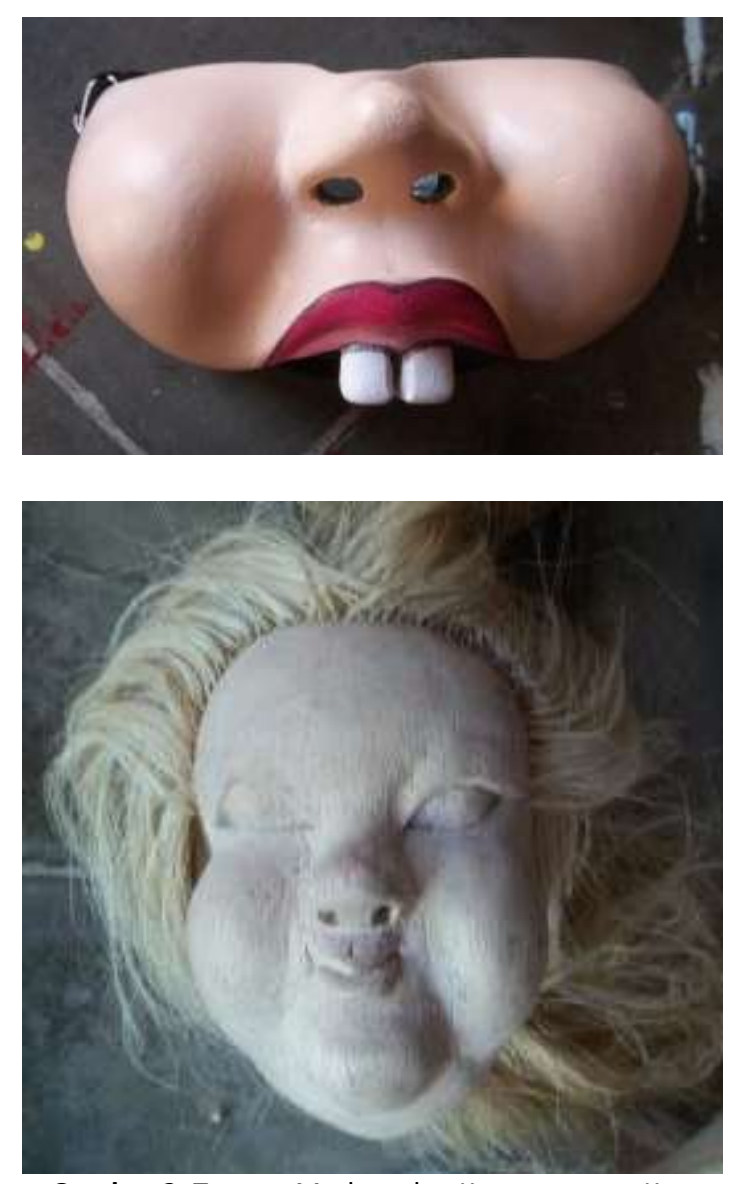

Gambar 2. Topeng Modern dan Kontemporer Karya Supana Ponowiguno

(Sumber: Dokumen Penulis, Juli 2017)

Seni tradisional adalah kesenian asli yang lahir dengan adanya dorongan emosi dan kehidupan batin yang murni atas dasar pandangan hidup dan kepentingan pribadi masyarakat pendukungnya (Bastomi, 2003: 48). Perkembangannya tergantung pada kondisi sosial budaya setempat dan persentuhan dengan masyarakat pendukung, serta pengaruh lingkungannya. Seni topeng Supana Ponowiguna adalah salah satu contoh sebagai kegiatan produktif yang dilakukan sebagian masyarakat yang merupakan sumber mata pencaharian. Pada mulanya topeng digunakan hanya sebagai fungsi aktif yaitu untuk pertunjukan tari pengganti tokoh. Akan tetapi topeng juga mempunyai fungsi pasif yang memiliki makna sarat dengan filosofi, baik digunakan untuk alat upacara, religi, maupun sebagai kegiatan seni tari yang juga mengandung unsur mistik.

$$
\text { Kegiatan ini mengalami }
$$
perkembangan dan perubahan baik fungsi, gaya, struktur, makna dan teknik, sesuai dengan arus perkembangan zaman. Seni topeng di Yogyakarta pada umumnya dan karya topeng Ponowiguna khususnya mengalami perubahan. Perubahan itu dapat kita lihat pada pengertian masyarakat tentang ketidakpahaman akan lakon suatu tokoh dan beberapa topeng klasik yang sarat akan nilainilai sakral yang ada dalam unsur seni topeng. Beberapa seni topeng juga memiliki jiwa dengan bentuk dan motif tertentu yang memiliki arti dan tujuan (sakral) berubah menjadi tidak memiliki arti (profan). Masyarakat modern sekarang sebagai pengguna seni topeng hanya mengetahui bahwa produk sebagai fungsi hias estetik elemen hias dan menjadi produk komersial.

Herbert Read dalam bukunya yang berjudul The Meaning of Art (1959), menyebutkan bahwa seni merupakan usaha manusia untuk menciptakan bentuk-bentuk yang menyenangkan. Bentuk yang menyenangkan dalam arti bentuk yang dapat membingkai perasaan keindahan dan perasaan keindahan itu dapat terpuaskan apabila dapat menangkap harmoni atau satu kesatuan dari bentuk yang disajikan (1959:1). Dari pernyataan di atas memberikan gambaran bahwa ekspresi manusia dapat dituangkan dalam suatu bentuk atau produk seperti karya seni topeng yang akan menggambarkan rasa kepuasaan batin seseorang dalam artian ialah si pencipta/kreator, dan juga kepuasaan batin bagi masyarakat luas yang dapat disebut sebagai penikmat karya yang menangkap harmonisasi rasa keindahan tersebut.

Kreasi seni topeng karya Supana Ponowiguno juga menangkap hal tersebut dengan membuat beberapa topeng sebagai wahana seniman untuk mengekspresikan jiwa pribadinya. Tetapi beliau juga sangat terbuka untuk membuat karya-karya seni topeng yang inspirasi kreatifnya berasal dari sang pemesan atau penikmat karyanya dengan berbagai bentuk dan ukuran sesuai dengan keinginan konsumen. Tetapi dalam setiap bentuk karya seni topeng yang diciptakan walaupun bukan dari keinginan pribadi, Supana Ponowiguna juga memberikan sentuhan kraesi dan karakter yang hidup pada seni topeng yang 
dia kerjakan. Hal ini sebagai wujud kecintaan beliau terhadap seni topeng agar topeng yang tercipta memiliki jiwa atau karakter yang hidup dan sebagai wahana untuk memberikan sentuhan akhir finishing touch rasa keindahan yang ingin dicapai pada setiap karya-karya topengnya.

.Karya-karya yang dibuat berdasarkan pesanan khusus dari penari-penari kenamaan Indonesia sebut saja Didik Nini Thowok, Miroto, dan penari-penari di Yogyakarta. Para seniman tersebut khusunya dalam seni pertunjukan tari sangat membutuhkan sentuhan kreatif Ponowiguna dalam menerjemahkan karakter yang dinginkan dalam tampilan seni pertunjukannya. Selain membuat topeng, Ponowiguna juga sering membuat boneka yang digunakan dalam adegan wayang yaitu Wayang Golekan yang mirip dengan wayang golek dari daerah Sunda. Patut menjadi perhatian kita bersama bahwa saat ini miskin regenerasi keahlian untuk membuat kreasi kreatif penciptaan seni topeng, khususnya untuk seni pertunjukkan tari. Ini yang menjadi tantangan kriyawan Yogyakarta dan pemerhati masyarakat penjaga budaya terutama dalam menjaga Yogyakarta tetap istimewa. Karena keahlian membuat topeng yang memiliki karakter akan terus dibutuhkan oleh teman-teman seni pertujukan karena dalam seni tari juga berlaku pengembangan seni yang diciptakan sesuai perkembangan zamannya, khususnya tari kreasi baru dan kontemporer.

Kita ambil contoh penari Didik Nini Thowok yang kerap sekali memberikan inovasi dan kreasi dalam seni tari yang membutuhkan topeng dalam menyampaikan imajinasi seni tarinya. Yang demikian itu, kreativitas seorang pencipta topeng dibutuhkan untuk menjawab kebutuhan yang diinginkan penari dengan segala bentuk dan karakter yang baru. Maka lahirlah karya topeng baru sebagai pemenuhan industry kreatif. Dengan ide dari para penari inilah kemudian muncul karyakarya seni topeng baru dengan semangat kreasi kreatif yang baru pula. Tak jarang dari nilai estetika secara visual dan mungkin seni topeng yang dibuat harus memiliki makna ditemukan bahan dan teknik baru dalam proses penciptaannya. Tentu hanya seniman kreatif yang akan memperoleh pengalaman estetik tersebut, sehingga akan menjadi laboratorium pribadi yang hanya dikuasai atau dimiliki oleh senimannya saja. Hal ini yang harus terus menjadi bahan kajian ilmiah yang dapat dilakukan dalam ranah penelitian agar transfer knowledge ilmu pembuatan seni topeng kreatif dapat ditularkan kepada generasi penrus.

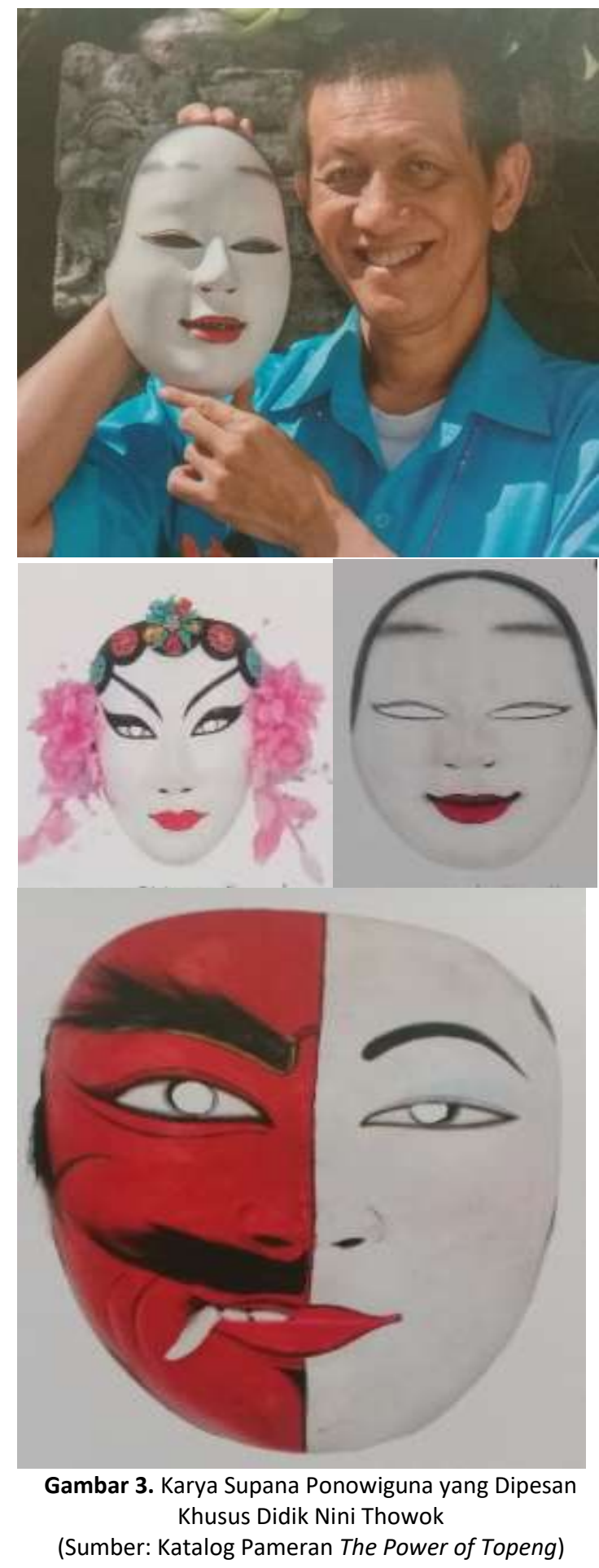




\section{Fungsi Seni Topeng Karya Supana Ponowiguno}

Menurut keterangan Supana

Ponowiguno bahwa pecinta seni topeng karya-karya beliau memang sebagian besar dibuat berdasarkan pesanan para penaripenari lokal, nasional, bahkan sampai dipesan oleh para konsumen dari luar negeri. Bahkan juga sering mendapatkan pesanan khusus dari berbagai muesum di Indonesia untuk melengkapi koleksi topeng di museummuseum nasional. Masuknya para pembeli dan pemesan seni topeng, bukan hanya membeli barang yang telah jadi, tetapi mereka juga membawa model barang atau desain dengan berbagai bentuk dan fungsi. Masuknya berbagai model dan desain baru yang dibawa oleh para pemesan, telah banyak menambah perbendaharaan jenis produk, bentuk, gaya dan karakter topeng yang dibuat. Salah satu hal yang menarik untuk diketahui adalah model atau desain baru yang diterima Supana Ponowiguno kadang dikerjakan sesuai aslinya atau tidak ada penggubahan tetapi ada yang sesuai bentuk aslinya dengan diberi sentuhan kreasi Supana Ponowiguno agar terlihat pas dengan karakter topengnya.

Melihat dari aneka ragam jenis barang yang diproduksi itu menunjukkan tingkat adaptasi yang sangat luwes dan kecakapan teknis Supana Ponowiguno yang tidak perlu diragukan. Selain jumlah dan jenis karya yang dihasilkan cukup banyak, ketelitian dan kualitas karya juga terjaga, terutama faktor kegunaan dan kualitas estetik yang menjadi prioritas utama dalam penciptaan karya seni topeng, baik sebagai benda fungsional untuk elemen estetis, kelengkapan seni pertunjukan tari dan wayang atau bahkan untuk koleksi pribadi maupun museummuseum sebagai wahana untuk mendidik para generasi muda melestarikan seni tradisional.

Dalam konteks tersebut, seni topeng karya Supana Ponowiguna dapat diamati menurut fungsinya. Feldman (1967) dalam bukunya yang berjudul Art Aslmage And Idea, terjemahan Gustami dengan judul Seni sebagai Wujud dan Gagasan (1991: 2) menjelaskan bahwa fungsi-fungsi seni yang telah berlangsung sejak zaman dahulu adalah untuk memuaskan: (1) Kebutuhan-kebutuhan individu tentang ekspresi pribadi; (2) Kebutuhan-kebutuhan sosial untuk keperluan display, perayaan, dan komunikasi; (3) Kebutuhan-kebutuhan fisik mengenai barangbarang dan bangunan-bangunan yang bermanfaat. Lebih jauh dalam pengertian luas Feldman membagi fungsi seni menjadi tiga bagian, yaitu: Fungsi personal (the personal function of art); fungsi sosial (the social function of art); dan fungsi fisik (the fisical function of art).

\section{a. Fungsi Personal}

Fungsi personal seni topeng merupakan wujud penyaluran gagasan bagi perajin atau sebagai saluran ekspresi pribadi. Ekspresi tersebut tidak hanya terbatas pada ilham saja yang semata-mata tidak berhubungan dengan emosi-emosi pribadi dan hal ihwal tentang kehidupan, tetapi juga mengandung pandangan-pandangan pribadi tentang peristiwa dan objek umum yang dekat dengan kehidupan, termasuk situasi kemanusiaan yang mendasar, seperti cinta, sakit, kematian, dan perayaan yang terulang secara konstan sebagai tema-tema seni. Tema-tema ini dapat dibebaskan dari kebiasaan, yang secara pribadi dan unik ditampilkan oleh seniman dengan ciri khasnya (Feldman, terjemahan SP. Gustami, bagian satu, 1991: 4), bagi kriyawan untuk memperlihatkan pandangan pribadinya melalui ekspresi estetiknya. Dalam beberapa hal, fungsi karya seni ialah sebagai media ekspresi pribadi seorang seniman (Feldman, terjemahan SP. Gustami, bagian satu, 1991: 6).

Bagi Supana Ponowiguno ekspresinya terlihat dari kesabaran, ketekunan, dan ketelitian dalam menyelesaikan hasil karyanya. Dalam hal ini beliau berusaha untuk membuat bentuk-bentuk topeng inovatif dengan memberikan sentuhan ukiran, warna, gaya, dan karakter yang baik. Hal itu memerlukan ketelitian dan teknik yang tinggi. Bahan dan teknik itu menjadi sarana berekspresi bagi perajin dalam proses penciptaan karya seni. Tanpa penggunaan dengan bahan khusus dan cara-cara spesifik, 
tampaknya tidak mungkin mendapatkan karya seni sesuai kondisi objektif, perasaan, dan kesadaran.

\section{b. Fungsi Sosial}

Seni topeng karya Supana Ponowiguno merupakan salah satu bentuk karya seni yang digunakan oleh masyarakat. Kebanyakan seni topengnya ini digunakan sebagai elemen hias dan untuk kebutuhan seni pertunjukan tari baik itu tradisi, modern, bahkan kontemporer. Sebab itu hasil karyanya menunjukkan fungsi sosial. Untuk mengetahui bagaimana fungsi sosial dapat mengacu pada pendapat Feldman yang menjelaskan bahwa karya seni menunjukkan fungsi sosial, apabila: (1) karya seni itu mencari atau cenderung memengaruhi perilaku kolektif orang banyak; (2) karya itu diciptakan untuk dilihat atau dipakai (dipergunakan), khususnya dalam situasi-situasi umum; dan (3) karya seni itu mengekspresikan atau menjelaskan aspekaspek tentang eksistensi sosial atau kolektif sebagai lawan dari bermacam-macam pengalaman personal individu (Feldman, terjemahan SP. Gustami, bagian satu, 1991: 61).

\section{c. Fungsi Fisik}

Seni topeng karya Supana Ponowiguno memiliki fungsi fisik ditentukan oleh segi estetik, nilai simbolik, dan nilai kepraktisan. Selain itu, keberhasilannya juga sangat ditentukan oleh tingkat keterampilan pembuatannya. Sejalan dengan pandangan Tjetjep Rohendi Rohidi menjelaskan bahwa fungsi fisik seni kentara ketika dilihat kesejajarannya dengan kebudayaan, yaitu fungsinya sebagai pedoman hidup, sistem simbol, dan strategi adaptasi terhadap lingkungannya (Rohidi, 2000: 267). Dari pengertian tersebut, fungsi fisik seni topeng dipandang dari sudut desain, terlihat lebih menekankan terpenuhinya tuntutan praktis dan keindahan penampilan barang. Baik keindahan bentuk maupun ornamentasinya, yang pada dasarnya mengandung makna simbolis, magis, dan spiritual tidaklah menjadi masalah. Mencermati seni kerajinan dari aspek fisik, berarti menunjuk pada karya yang ada kaitannya langsung dengan pemenuhan kebutuhan masyarakat sebagai elemen hias rumah.

\section{Gaya Seni Topeng Karya Supana Ponowiguno}

Berkaitan dengan gaya seni, Agus Sachari menjelaskan bahwa gaya seni akan dipengaruhi oleh zamannya. Secara umum, tumbuhnya keragaman gaya pada dunia desain dan seni rupa dibentuk oleh kebudayaan yang berkembang saat itu. Namun aspek maknawi tetap merupakan suatu proses penyadaran, bahwa nilai-nilai estetik menjadi bagian penting dalam proses transformasi budaya (2002: 127). Hal ini juga tampak pada produk seni topeng karya Supana Ponowiguna yang mengalami perubahan. Perubahan disebabkan oleh pengaruh yang masuk dan diterima dengan baik oleh beliau dalam penciptaan karya-karya kreatif. Yang pada akhirnya nilai sakral yang dimiliki mulai lebur menjadi kebutuhan seni hias estetik saja, walaupun juga beberapa masih memegang peranan spiritualnya.

Gaya seni atau corak seni sebenarnya berurusan dengan bentuk luar suatu karya seni, sedangkan aliran atau faham menyangkut pandangan atau prinsip yang lebih dalam sifatnya. Aliran atau gaya timbul karena sesuatu kebutuhan, yang dengan sadar ingin dicapai melalui karya-karya. Karena ada perbedaan konsepsi pikiran dari tiap-tiap zaman, lahirlah kesenian yang mempunyai ciri-ciri khusus. Adanya bermacam-macam gaya atau corak yang mempunyai pesona tersendiri, khusus, dan khas. Dengan gaya seni akan memimpin seorang untuk mencari makna-makna dibalik "sudject mater" dan tujuan yang tampak dari sebuah karya seni (Feldman, terjemahan SP. Gustami bagian dua, 1991: 3).

Seni topeng karya Supana Ponowiguno merupakan bentuk karya yang memiliki ciri khas dan dipertahankan secara turun-tumurun. Seni hias ini mengalami perkembangan dan perubahan setelah bersentuhan dengan kebudayaan baru yang membawa kesenian baru. Seni hias topeng karya Supana Ponowiguno memiliki karakteristik yang berangsur-angsur mengalami perkembangan yang ditimbulkan karena pengaruh dari luar tetapi karya seni topeng dapat dikategorikan ke dalam gaya tradisional. Bentuk topeng yang dihasilkan 
menghadirkan suatu karya yang penuh dengan variasi, hadir dengan irama yang harmonis terkesan luwes, memiliki kerumitan yang cukup tinggi dan mencapai tingkat kesempurnaan yang sulit diubah untuk memperoleh hasil yang lebih baik. Hal ini memunculkan sebuah bentuk karya seni yang memiliki karakter kolektif sebagai ciri khas gaya yang muncul khususnya seni topeng gaya Yogyakarta.

\section{Struktur Seni Topeng Karya Supana Ponowiguno}

Dalam mengamati karya seni, $\mathrm{M}$. Dwi Marianto (2002: 2) menjelaskan bahwa ada tiga hal utama dalam dimensi karya seni yang bersangkutan, yaitu: subject matter, medium, dan form. Materi subjek (subject matter) dalam karya seni adalah figur-figur, objekobjek, tempat-tempat dan peristiwa yang dilukiskan dalam suatu karya seni. Maka produk seni topeng karya Supana Ponowiguno tersusun dari objek-objek yang diolah sedemikian rupa dalam wujud seni hias ukir kayu. Dapat dilihat dari materi subjek yang hadir misalnya motif-motif tradisional, teknik sunggingan, dan sebagainya.

Djelantik menjelaskan bahwa struktur karya seni adalah aspek yang menyangkut keseluruhan dari karya seni dan meliputi juga peranan masing-masing bagian dalam keseluruhan karya seni tersebut. Kata struktur mengandung arti bahwa di dalam karya seni terdapat suatu pengorganisasian, penataan, yang ada keterkaitan atau hubungan tertentu antara bagian-bagian yang tersusun. Termasuk dalam hal ini adalah barang-barang hasil kerajinan (handicraft) dari semua jenis kesenian, yang ditampilkan dan dinikmati mengandung dua unsur yang mendasar, yakni bentuk (form) dan struktur tatanan (susunan). Bentuk-bentuk yang mendasar dari seni rupa adalah titik, garis, bidang, ruang dan warna. Struktur atau susunan dimaksud adalah cara-cara bagaimana unsur-unsur dasar tersebut tersusun hingga menjadi wujud (Djelantik, 2004: 18)

Adapun form atau bentuk suatu karya seni adalah setiap karya seni memiliki bentuk, baik bentuk yang hadir sebagai bentuk kubus, segitiga, persegi panjang, dan lain sebagainya, sehingga yang dimaksud adalah bagaimana para perajin menyampaikan materi subjek karyanya melalui medium yang dipergunakan. Secara keseluruhan seni topeng dapat dikategorikan pada jenis seni ukir tradisional.

\section{PENUTUP}

Keberadaan seni topeng di Yogyakarta masih dapat dikatakan baik, karena para pelaku perajin atau kriyawannya masih eksis melakukan kreasi inovatif untuk menciptakan topeng-topeng kreatif. Dari perjalanannya masih ditemukan pelaku kriya yang masih eksis membuat topeng klasik gaya Yogyakarta sampai pada kebutuhan seni topeng kontemporer. Kekayaan sumber daya alam yang melimpah di Indonesia tidak menutup kreativitas untuk menciptakan topeng-topeng terbarukan, baik dari segi bentuk, teknik, finishing, dan aplikasi bahan yang memunculkan diversifikasi tetapi tetap memiliki nilai estetika. Ketersediaan insaninsan kreatif juga terus mengalir walau dari segi jumlah memang menurun. Realitas ini memang menjadi fakta kehidupan untuk menyadarkan kita akan potensi yang belum tergarap secara maksimal seperti potensi seni topeng yang masih banyak membutuhkan pengembangan dan kajian ilmiah, sehingga karya topeng tidak hanya sempit dinilai sebagai sarana dalam seni pertunjukan saja tetapi bisa dikembangkan menjadi karya seni rupa.

Yang patut menjadi catatan dan perhatian bagi semua pihak masyarakat penyangga budaya, khususnya Yogyakarta sebagai kota budaya yang kuat dengan ikon Yogya Istimewa ialah regenarisasi pembuat topeng khusus untuk sarana pertunjukan seni tari. Terlebih lagi keberadaan seniman tradisi pembuat topeng yang memilki keahlian dalam memunculkan karakter tokoh seperti Supana Ponowiguno. Pembelajaran dan transfer knowledge dalam menciptakan seni topeng gaya tradisi, modern, sampai pada bentukbentuk kontemporer sangat dibutuhkan ruang dan waktu yang harus terus diberikan kepada regenerasi penerusnya. Karena tidaklah mudah menciptakan sebuah karakter suatu tokoh dalam proses pembuatannya dengan 
pemilihan bahan, teknik, dan finishing yang tepat.

Topeng Karya Supana Ponowiguno mengedepankan bentuk, kreasi, dan mengutamakan topeng gaya Yogyakarta serta mengikuti perkembangan seni topeng karya kreatif modern dan kontemporer dalam menjawab kebutuhan global. Eksistensi Supana Ponowiguno yang terus mendedikasikan hidupnya bagi dunia seni rupa dalam menciptakan seni topeng yang sarat dengan bentuk visual yang estetik bahkan sarat dengan makna mengandung nilai religius yang patut mendapatkan apresiasi yang tinggi dari pemerintah, lembaga pendidikan seni, bahkan masyarakat penyangga seni budaya di Yogyakarta. Hal ini perlu dilakukan sebagai bentuk penghargaan kepada para pejuang tradisi di zaman modern sekarang yang menuntut perubahan yang sangat cepat, sehingga para penjuang tradisi tersebut akan tetap terus survive dalam memberikan hidup dan ilmunya kepada para penerus budaya bangsa agar ciri lokal genius Yogyakarta pada khususnya dan Indonesia pada umumnya akan tetap menjadi aset kekayaan budaya bangsa yang membanggakan.

\section{DAFTAR PUSTAKA}

Dana, I Wayan. 2015. The Power of Topeng. Katalog Pameran Museum Sonobudoyo Yogyakarta.

Feldman, Edmund Burke. 1967. Art As Image and Idea. New Jersey: Prentice hall, Inc. Englewood Cliffs

Gustami, SP. 2000. Seni Kerajinan Mebel Ukir Jepara, Kajian Estetik melalui Pendekatan Multidisiplin. Yogyakarta: Kanisius.

. 2003. "Metode Pendekatan dalam Kajian Seni Rupa." dalam Bunga Rampai Kajian Seni Rupa, dalam Kenangan Purnatugas Prof. Drs. Suwaji Bastomi. Semarang: UNNES Press.

Marianto M. Dwi. 2002. Seni Kritik Seni. Lembaga Penelitian Seni Institut Seni Indonesia Yogyakarta
Museum Sonobudoyo Yogyakarta. 2015. The Power of Topeng Katalog Pameran. Yogyakarta.

Read, Herbert. 1959. The Meaning of Art. New York: Pinguin Book.

Rohidi, Tjejep Rohendi. 2000. Ekspresi Seni Orang Miskin: Adaptasi Simbolik terhadap Kemiskinan. Bandung: Yayasan Adikarya IKPI dan Ford Foundation.

Sachari, Agus. 2002. Estetika Makna Simbol dan Daya. Bandung: ITB.

Soedarsono, R.M. 1999. Metodologi Penelitian Seni Rupa dan Pertunjukan. Bandung: Masyarakat Seni Pertunjukan Seni Indonesia.

Tim Penyusun Departemen Pendidikan dan Kebudayaan Direktorat Jendral Kebudayaan Museum Sonobudoyo Yogyakarta. 1987. Gaya dan Daya Tarik Topeng. Yogyakarta. 